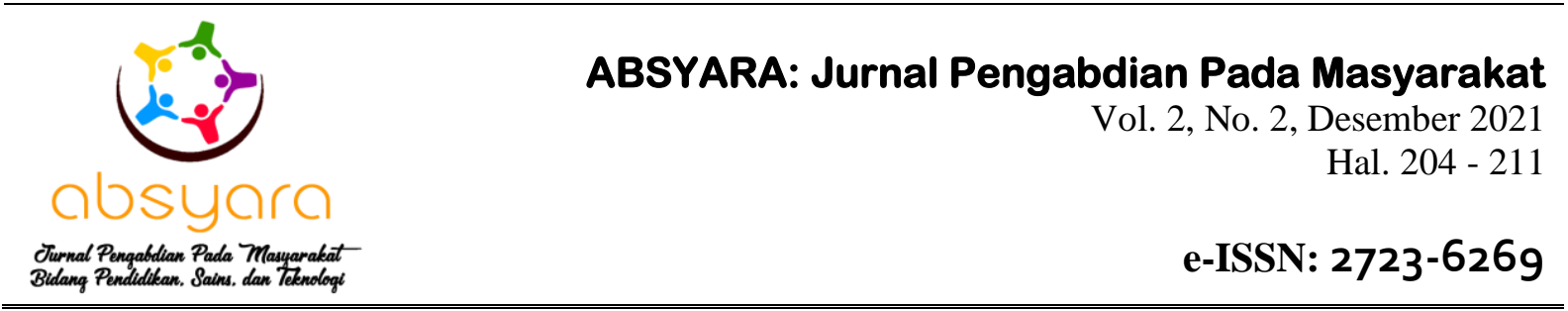

\title{
Pelatihan Penggunaan Aplikasi Inventaris Gudang Puskesmas Sakra
}

\author{
Hamzan Ahmadi*1, Aris Sudianto², Hadian Mandala Putra ${ }^{3}$, M. Iman Darmawan ${ }^{4}$ \\ 1*anonymouse.https@gmail.com \\ 1,2 Teknik Informatika, Fakultas Teknik Universitas Hamzanwadi \\ ${ }^{3}$ Teknik Komputer, Fakultas Teknik Universitas Hamzanwadi \\ ${ }^{4}$ Teknik Lingkungan, Fakultas Teknik Universitas Hamzanwadi
}

Received: 30 October 2021 Accepted: 06 December 2021 Online Publisher: 30 December 2021 DOI: 10.29408/ab.v2i2.4204

\begin{abstract}
Abstrak: Sistem inventaris merupakan suatu sistem yang mengelola data barang-barang yang dimiliki suatu kantor. Memiliki sistem inventaris yang baik akan membantu suatu perusahaan dalam mengelola data barang yang dimiliki oleh perusahaan tersebut. Tidak hanya perusahaan besar yang membutuhkan sistem inventaris, akan tetapi kantor yang kecil juga membutuhkan sistem inventaris. Demikian pula dengan Puskesmas, dalam mengelola data-data seperti obat, perlengkapan medis, alat tulis dan sebagainya membutuhkan sistem inventaris gudang yang baik. Oleh karena itu, kegiatan pengabdian ini bertujuan untuk mengembangkan dan memberikan pelatihan tentang aplikasi Inventaris Gudang Puskesmas. Mitra dari kegiatan ini adalah Puskesmas Sakra (tenaga administrasi). Metode yang digunakan yaitu ceramah, pendampingan, dan praktik langsung menggunakan aplikasi. Hasil dari pengabdian ini adalah terbentuknya produk perangkat lunak inventaris gudang Puskesmas Sakra, dan tenaga administrasi yang diberi pelatihan mampu mengoperasikan perangkat lunak tersebut.
\end{abstract}

Kata kunci: Pelatihan; Pusat Kesehatan Masyarakat; Sistem Inventaris Gudang

\begin{abstract}
An inventory system is a system that manages data on items owned by an office. A good inventory system will help a company manage data on goods owned by the company. Not only do big companies need an inventory system, but small offices also need an inventory system. Likewise, with the Health Center, managing data such as drugs, medical equipment, stationery, etc., requires a good warehouse inventory system. Therefore, this service activity aims to develop and train the Health Center Warehouse Inventory application. The partner of this activity is the Sakra Community Health Center (administrative staff). The methods used are lectures, mentoring, and direct practice using applications. The result of this activity is the production of warehouse inventory system software for the Sakra Health Center. In addition, the Sakra Health Center's administrative staff can also run the software.
\end{abstract}

Keywords: Community Health centers; Training; Warehouse Inventory System 
Ahmadi, H., Sudianto, A., Putra, H. M., Darmawan, M., I. (2021). Pelatihan penggunaan aplikasi Inventaris Gudang Puskesmas Sakra. ABSYARA: Jurnal Pengabdian Pada Masyarakat, 2(2), 204-211. doi:10.29408/ab.v2i2.4204

\section{PENDAHULUAN}

Perkembangan ilmu pengetahuan dan teknologi yang semakin pesat tidak hanya memiliki banyak dampak positif saja namun juga dapat memiliki dampak yang negatif dalam berbagai bidang kehidupan. Pemanfaatan teknologi komputer membuat pengolahan data dan informasi dapat dilakukan dengan cepat dan akurat. Selain itu dengan pemanfaatan teknologi komputer, khususnya yang melibatkan jaringan internet yang dapat dipakai dalam proses penyebaran informasi yang lebih efektif dan efisien (Wulandari, dkk., 2015). Kemajuan teknologi dan informasi ini juga memberikan banyak kemudahan dalam pengolahan data inventaris barang di suatu organisasi tidak terkecuali inventaris untuk gudang di puskesmas Sakra.

Implementasi dari mata kuliah Pemrograman dapat dilakukan dengan berbagai macam cara, diantaranya adalah dengan terjun langsung untuk membuat suatu Project nyata seperti perancangan inventaris gudang puskesmas Sakra. Penerapan hasil pembelajaran pada mata kuliah pemrograman merupakan salah satu cara yang ditempuh untuk dapat meningkatkan pemahaman bagi mahasiswa, hal ini dikarenakan hasil produk yang dihasilkan dapat terlihat nyata dan siap untuk digunakan, sehingga mahasiswa dapat mengetahui seperti apa penerapan materi yang diberikan pada mata kuliah pemrograman yang sebenarnya dalam kehidupan sehari-hari (Suhartini, dkk., 2021). Penelitian yang sudah pernah dilakukan sebelumnya tentang edukasi Zero Waste berbasis teknologi informasi, metode yang paling tepat digunakan untuk edukasi berbasis teknologi informasi ini adalah metode praktik (Wirasasmita, dkk., 2020). Hasil yang didapatkan yaitu terbentuknya suatu aplikasi sistem informasi berupa aplikasi Zero Waste yang dapat diakses menggunakan perangkat berbasis android.

Inventaris merupakan suatu cara dalam pengelolaan aset suatu instansi atau organisasi yang dilakukan dengan baik agar kegiatan operasional suatu organisasi dapat berjalan dengan baik (Susandi \& Sukisno, 2018). Secara umum kegiatan dalam inventarisasi barang merupakan suatu proses untuk melakukan pencatatan pengadaan barang, penempatan barang, mutasi barang sampai dengan pemeliharaan barang di suatu organisasi atau instansi sehingga barang yang telah diinventaris tersusun menjadi lebih baik (Kurniawan \& Nurgiyatna, 2019).

Dengan penerapan hasil pembelajaran pada mata kuliah pemrograman menjadi suatu Project nyata yang dapat dijadikan sebagai hasil pembelajaran oleh mahasiswa yang tentunya dapat menarik minat dan antusias mahasiswa dalam mengembangkan produk-produk yang lainnya. Sebagai salah satu contoh Penerapan Produk Hasil Penelitian Sistem Informasi Geografis (GIS) Untuk Pemetaan Kerajinan Kain Tenun Dan Gerabah Berbasis Web merupakan salah satu langkah yang diambil untuk dapat memberikan pemahaman kepada siswa terhadap cara merancang aplikasi secara nyata dan dampaknya terhadap masyarakat (Sudianto, 2018). Dari hasil perancangan sistem yang dilakukan oleh mahasiswa sebagai bentuk implementasi dari program merdeka belajar ini dapat sangat bermanfaat bagi instansi maupun organisasi yang dibuatkan aplikasi inventaris dalam kasus ini adalah Puskesmas Sakra dapat membantu dalam memanajemen barang yang ada di gudang dengan lebih baik, sehingga daftar barang juga menjadi lebih rapi dan terstruktur (Setiadi, dkk., 2015). 
Ahmadi, H., Sudianto, A., Putra, H. M., Darmawan, M., I. (2021). Pelatihan penggunaan aplikasi Inventaris Gudang Puskesmas Sakra. ABSYARA: Jurnal Pengabdian Pada Masyarakat, 2(2), 204-211. doi:10.29408/ab.v2i2.4204

\section{METODE PELAKSANAAN}

\section{Waktu dan tempat}

Pelaksanaan kegiatan pengabdian kepada masyarakat (PKM) ini dilaksanakan sejak bulan Juli sampai bulan Oktober 2021. Pelaksanaan kegiatan implementasi hasil pembelajaran mata kuliah pemrograman dengan perancangan aplikasi inventaris gudang dilakukan di puskesmas Sakra. Untuk pelaksanaan kegiatan PKM ini dilakukan secara bertahap dengan skema yaitu dimulai dengan tahap analisis dan survei lokasi untuk mencari informasi seputar perancangan yang akan dibuat. Pada tahapan ini semua data diambil dari puskesmas Sakra. Tahapan selanjutnya adalah implementasi hasil analisis ke dalam sistem pemodelan untuk dibuat model sistem yang akan dibangun. Setelah itu dilanjutkan untuk tahap perancangan desain user interface yang sesuai dengan yang diinginkan oleh instansi. Dan tahapan akhir adalah implementasi dan pengujian sistem, untuk melihat apakah sistem dapat berjalan dengan baik atau masih harus ada yang disesuaikan kembali

\section{Prosedur pelaksanaan}

Di dalam pelaksanaannya kegiatan PKM ini terdiri atas beberapa tahapan kegiatan yaitu :

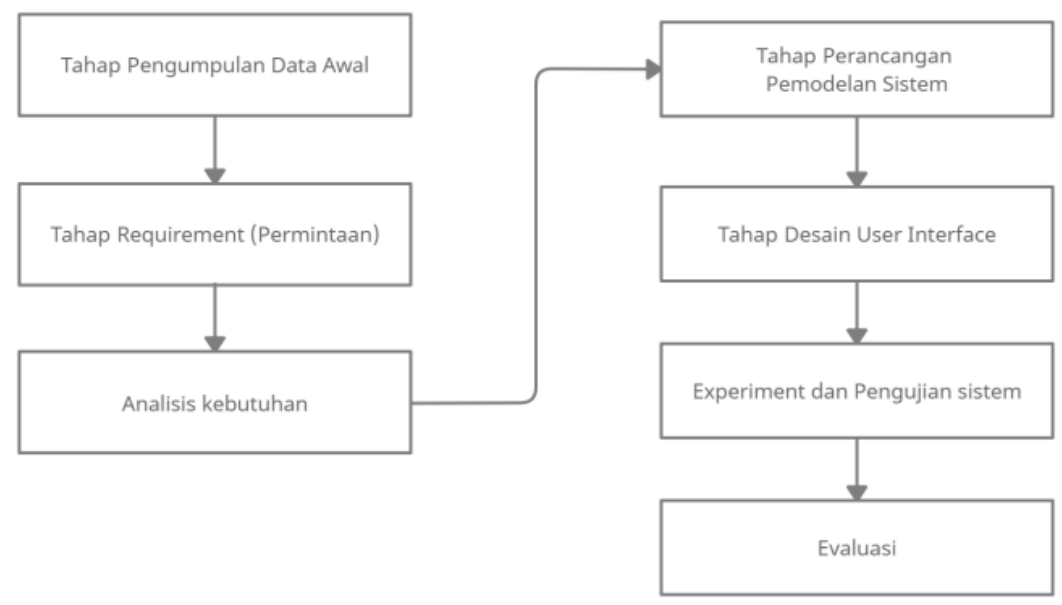

Gambar 1. Tahapan dalam kegiatan pengabdian masyarakat

- Tahap Pengumpulan Data Awal.

Tahap pengumpulan informasi mengenai data - data yang dibutuhkan untuk perancangan aplikasi inventaris gudang pada puskesmas Sakra, informasi yang dibutuhkan di dapat langsung dari pengelola atau staf yang adai di puskesmas Sakra.

- Tahap Requirement ( Permintaan )

Pada tahapan requirement (permintaan) ini ditujukan untuk dapat mengarahkan staf yang ada di puskesmas Sakra agar sesuai dengan apa yang ingin dikerjakan pada pengabdian ini. Pada tahapan ini dilakukan penyaringan data mana saja yang akan di jadikan calon atau kandidat requirement.

- Analisis

Pada tahap analisis ini bertujuan untuk mendapatkan suatu pemahaman secara menyeluruh terhadap penerapan pembelajaran untuk mata kuliah pemrograman yang 
akan dilakukan, berdasarkan kebutuhan apa saja yang harus dipersiapkan, termasuk pemilihan bahasa pemrograman yang akan digunakan.

- Tahap perancangan pemodelan perangkat lunak.

Pada tahapan ini, dilakukan suatu proses penyusunan kerangka pemodelan yang dibutuhkan dalam menyelesaikan kegiatan ini (perancangan aplikasi inventaris gudang). Pemodelan yang dilakukan terdiri dari algoritma, flowchart maupun penggunaan UML.

- Tahap Desain User interface

Pada tahapan ini dilakukan perancangan desain user interface untuk pembuatan aplikasi inventaris gudang yang sesuai dengan kebutuhan yang ada di puskesmas.

- Eksperimen dan Pengujian.

Hasil Pemetaan yang telah dilakukan, di uji coba untuk melihat apakah aplikasi yang telah dibuat dapat sesuai dengan yang diinginkan peneliti.

- Evaluasi hasil eksperimen dan pengujian.

Setelah dilakukan pengujian dan eksperimen terhadap hasil yang dilakukan, maka bisa dilihat perbedaan dari hasil yang dilakukan sebelumnya, apakah dengan pembuatan aplikasi inventaris tersebut dapat berdampak pada peningkatan efektivitas dan kecepatan dalam pengelolaan data yang ada pada puskesmas.

Kegiatan pengabdian masyarakat ini diharapkan dapat menambah pengetahuan mahasiswa terhadap implementasi dari pembelajaran yang telah dilakukan, dalam hal ini adalah pembelajaran pada mata kuliah pemrograman. Setidaknya mahasiswa mulai bisa memahami bahwa selama ini banyak hal yang dapat diperoleh sebagai hasil dari implementasi pembelajaran untuk meningkatkan kompetensi keahlian dari mahasiswa. Sehingga nantinya setelah lulus mahasiswa memiliki bekal pengetahuan yang lebih baik.

\section{HASIL DAN PEMBAHASAN HASIL}

Dalam pelaksanaan penerapan hasil pembelajaran pada mata kuliah pemrograman untuk perancangan aplikasi inventaris gudang puskesmas Sakra ini telah berjalan dengan baik. Pelaksanaannya dilaksanakan mulai dari bulan Juli sampai dengan bulan November tahun 2021, namun demikian masih ada fitur-fitur yang harus dikembangkan pada sistem sehingga membuat sistem ini diprediksi bisa lengkap secara keseluruhan sekitar bulan Desember tahun 2021. Dalam penelitian yang sebelumnya telah dilakukan yaitu pelatihan uji kompetensi siswa untuk bidang multimedia diperoleh hasil bahwa adanya pelatihan kompetensi keahlian khususnya dalam bidang multimedia ini, diharapkan dapat membantu siswa dalam mempersiapkan ujian kompetensi keahlian untuk mendapatkan hasil yang maksimal (Putra, dkk., 2020; Rosita, 2021). Dalam pelaksanaan penerapan implementasi pembelajaran materi pemrograman dilakukan secara bertahap. Dengan melaksanakan kegiatan ini kompetensi yang dimiliki oleh mahasiswa menjadi lebih baik dari sebelumnya baik dari segi pengetahuan maupun dari segi keterampilan. Dengan mengikuti kegiatan ini mahasiswa dituntut untuk lebih mandiri dalam menyelesaikannya, terlebih lagi mahasiswa dituntut untuk lebih mandiri dalam belajar dan mencari sumber referensi untuk digunakan sebagai pendukung dalam menyelesaikan pekerjaan pembuatan inventaris gudang ini. 
Ahmadi, H., Sudianto, A., Putra, H. M., Darmawan, M., I. (2021). Pelatihan penggunaan aplikasi Inventaris Gudang Puskesmas Sakra. ABSYARA: Jurnal Pengabdian Pada Masyarakat, 2(2), 204-211. doi:10.29408/ab.v2i2.4204

Selain mendapatkan hasil yang bermanfaat dan nyata dari kegiatan ini, mahasiswa juga menjadi lebih baik dalam kompetensi, menjadi lebih paham bagaimana skema dan struktur dalam perancangan suatu sistem dalam kasus ini adalah sistem inventaris gudang.

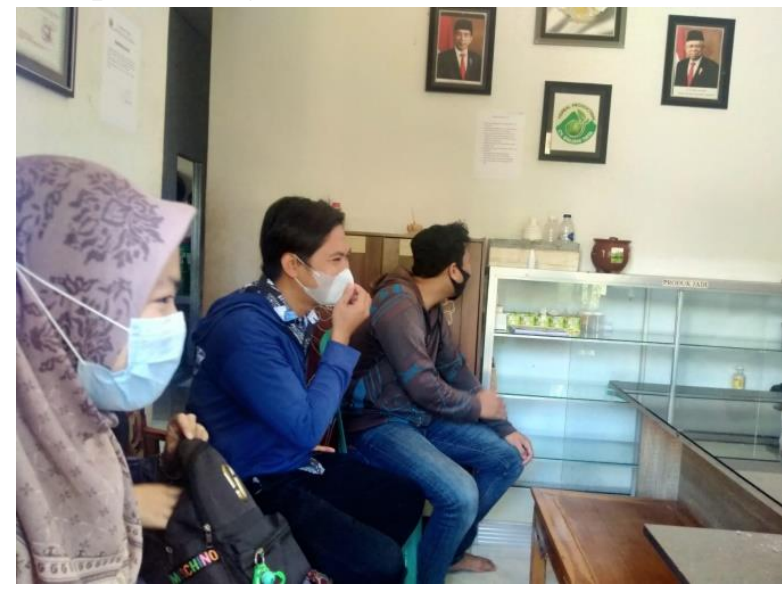

Gambar 1. Survei Lokasi

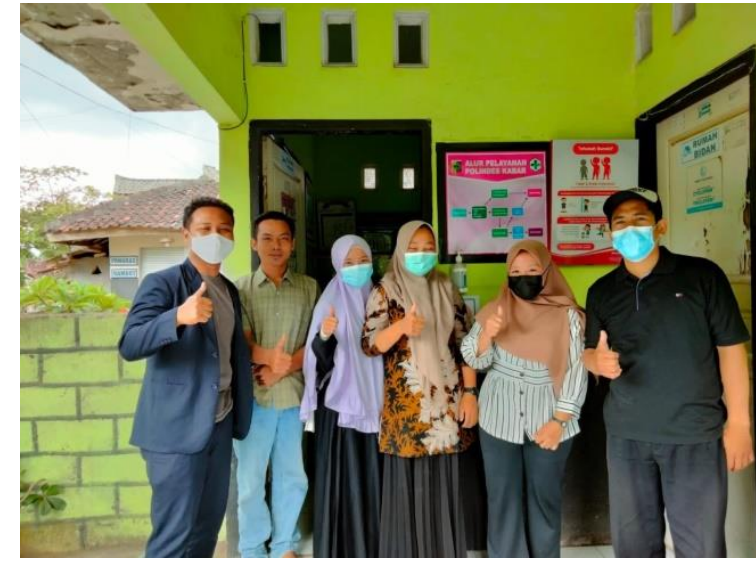

Gambar 2. Kegiatan pengambilan data

Dalam praktik pelaksanaan kegiatan ini mahasiswa memang benar-benar dituntut untuk lebih mandiri dan berusaha keras dalam menyelesaikan tiap tahapan kegiatan, selain itu juga mahasiswa didampingi oleh trainer dalam melaksanakan kegiatan di bawah instruksi dan bimbingan dari dosen pembimbing. Dalam penerapan hasil pembelajaran pada matakulah pemrograman untuk perancangan aplikasi inventaris gudang Puskesmas di Sakra ini dilaksanakan dengan skema tahap awal yang dimulai di awal bulan Juli yaitu pelaksanaan survei lokasi yaitu menentukan tempat yang akan dijadikan sebagai objek lokasi pengabdian kepada masyarakat. Dari informasi yang diterima melalui salah satu mahasiswa maka dari itu diambillah puskesmas Sakra sebagai tempat pelaksanaan kegiatan. Adapun hasil yang diperoleh dari pelaksanaan kegiatan ini adalah sebagai berikut:

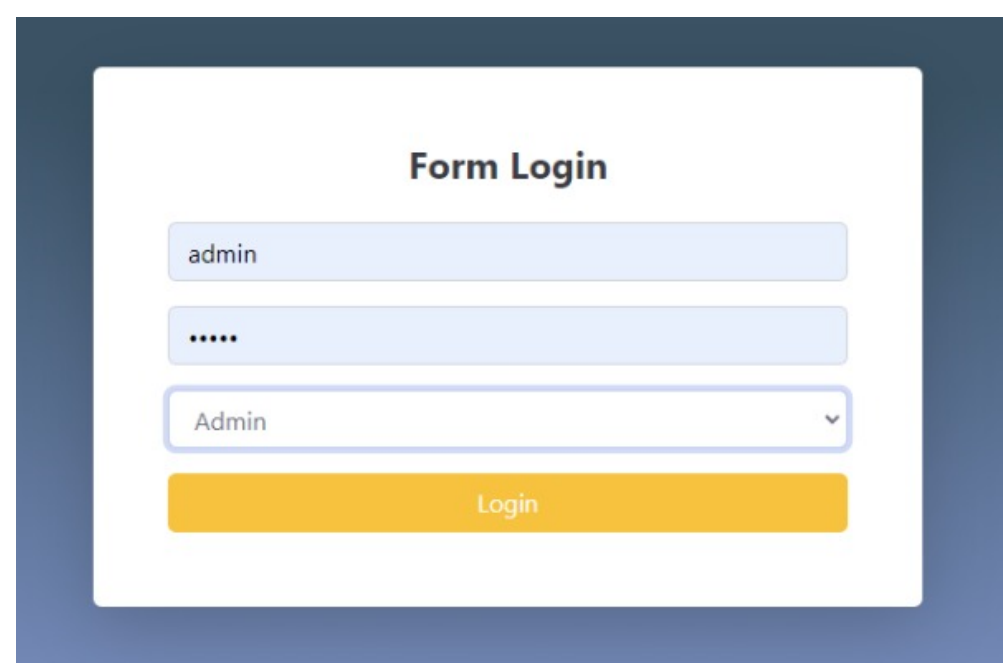

Gambar 3. Tampilan Log in Sistem 
Ahmadi, H., Sudianto, A., Putra, H. M., Darmawan, M., I. (2021). Pelatihan penggunaan aplikasi Inventaris Gudang Puskesmas Sakra. ABSYARA: Jurnal Pengabdian Pada Masyarakat, 2(2), 204-211. doi:10.29408/ab.v2i2.4204

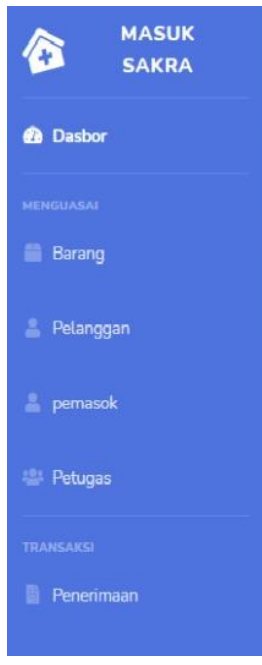

Halaman Dasbor

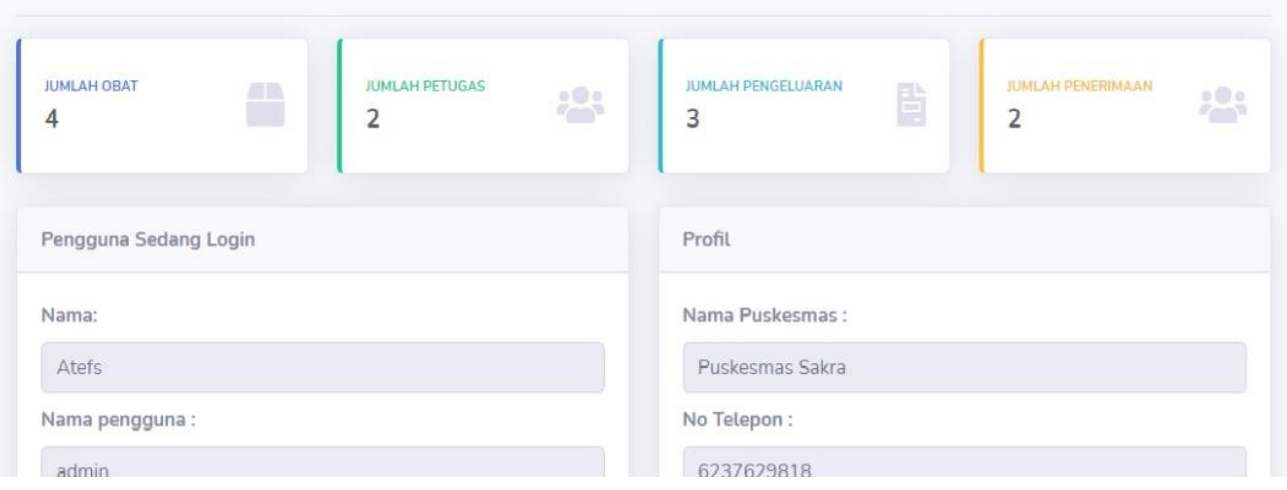

Gambar 4. Halaman Beranda Aplikasi

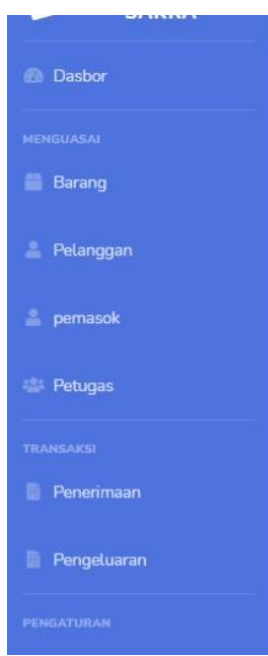

Profil Puskesmas

Isi Form Dibawah Ini!

Nama Puskesmas :

Puskesmas Sakra

No Telepon

6237629818

alamat

J. Soekarno Hatta, Suangi, Sakra, Kabupaten Lombok Timur, Nusa Tenggara Bar. 83671, Indonesia

Q simpan Ubah $\times$ Batal

Gambar 5. Halaman Profil Aplikasi Inventaris Gudang

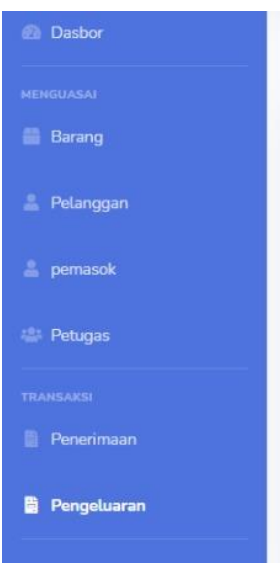

Transaksi Pengeluaran

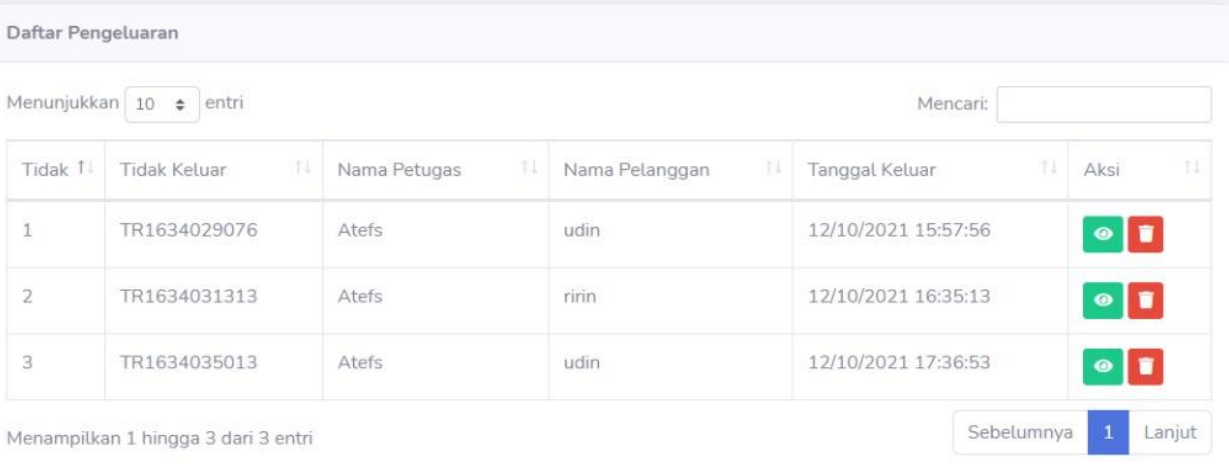

Gambar 6. Halaman Transaksi Pengeluaran Aplikasi Inventaris gudang 
Ahmadi, H., Sudianto, A., Putra, H. M., Darmawan, M., I. (2021). Pelatihan penggunaan aplikasi Inventaris Gudang Puskesmas Sakra. ABSYARA: Jurnal Pengabdian Pada Masyarakat, 2(2), 204-211. doi:10.29408/ab.v2i2.4204

\section{PEMBAHASAN}

Sistem informasi inventaris berbasis web merupakan suatu sistem yang dapat digunakan untuk membantu operator maupun staf di suatu organisasi atau instansi dalam memanajemen data barang (Oktaviani , dkk., 2019). Dari hasil kegiatan pelaksanaan penerapan hasil pembelajaran pada mata kuliah pemrograman untuk perancangan aplikasi inventaris gudang puskesmas di Sakra ada beberapa hal positif yang didapatkan khususnya oleh Fakultas Teknik Universitas Hamzanwadi yaitu selain terealisasinya hasil dari pembelajaran mata kuliah pemrograman menjadi suatu yang nyata dan dapat berguna bagi instansi juga menghasilkan hubungan kerja sama antara fakultas teknik dengan instansi dalam hal ini adalah puskesmas Sakra. Dari hasil kegiatan yang telah dilaksanakan puskesmas berharap agar kegiatan dapat berlanjut di tahun-tahun berikutnya, mengingat perkembangan teknologi dan juga kebutuhan akan penggunaan teknologi sewaktu-waktu dapat berubah. Dari hasil yang diperoleh setelah melaksanakan kegiatan pengabdian ini, bahwa didapatkan hasil berupa terciptanya suatu aplikasi inventaris untuk gudang yang ada di puskesmas, dengan adanya aplikasi sangat membantu dalam penginventarisan data barang yang ada pada gudang puskesmas, aplikasi ini mampu berjalan dengan baik pada perangkat yang terhubung dengan koneksi internet. Dengan adanya pelaksanaan kegiatan pengabdian masyarakat yang mengambil tema penerapan mata kuliah pemrograman untuk perancangan suatu aplikasi inventaris gudang di puskesmas, menjadikan mahasiswa menjadi lebih terampil dan kompeten terhadap apa yang telah dipelajari, dengan kegiatan ini kemampuan mahasiswa menjadi lebih baik, dikarenakan mahasiswa tidak hanya sekedar membuat setengah saja, melainkan mahasiswa harus bertanggung jawab sampai aplikasi tersebut benar-benar dapat digunakan.

\section{SIMPULAN}

Dalam pelaksanaan kegiatan penerapan hasil pembelajaran mata kuliah pemrograman untuk merancang suatu aplikasi inventaris gudang pada puskesmas Sakra dapat disimpulkan bahwa kegiatan pembuatan aplikasi masih berjalan sampai sekarang untuk tahap pengembangan fitur-fitur yang dibutuhkan di puskesmas. Mahasiswa masih terus mengembangkan sistem menjadi lebih baik lagi, untuk sementara ini sistem telah dapat digunakan untuk penyimpanan data inventaris gudang, walaupun dengan tampilan yang masih sederhana.

\section{PERNYATAAN PENULIS}

Artikel ini belum pernah dipublikasikan di jurnal mana pun.

\section{DAFTAR PUSTAKA}

Kurniawan, D., \& Nurgiyatna, S. T. (2019). Perancangan Sistem Informasi Inventaris Gereja GBIS Nusukan Berbasis Web (Doctoral dissertation, Universitas Muhammadiyah Surakarta).

Oktaviani, N., Widiarta, I. M., \& Nurlaily. (2019). Sistem Informasi Inventaris Barang Berbasis Web Pada Smp Negeri 1 Buer. Jurnal Informatika, Teknologi Dan Sains, 1(2), 160168. https://doi.org/10.51401/jinteks.v1i2.422

Putra, Y. K., Sadali, M., Fathurrahman, F., \& Mahpuz, M. (2020). Pelatihan uji kompetensi 
Ahmadi, H., Sudianto, A., Putra, H. M., Darmawan, M., I. (2021). Pelatihan penggunaan aplikasi Inventaris Gudang Puskesmas Sakra. ABSYARA: Jurnal Pengabdian Pada Masyarakat, 2(2), 204-211. doi:10.29408/ab.v2i2.4204

keahlian siswa sekolah kejuruan menggunakan metode Participatory Learning and Action (PLA). ABSYARA: Jurnal Pengabdian Pada Masyarakat, 1(2), 46-52. https://doi.org/10.29408/ab.v1i2.2772

Rosita, F. Y. (2021). Pelatihan jurnalistik pada redaktur majalah sekolah Serambi AlMuayyad. ABSYARA: Jurnal Pengabdian Pada Masyarakat, 2(1), 32-40.

Setiadi, I. M. D., Piarsa, I. N., Made, N., \& Marini, I. (2015). Sistem Informasi Geografis Pemetaan Tingkat Pertumbuhan Penduduk Berbasis Web. 3(3), 180-189.

Sudianto Aris, S. M. (2018). Penerapan Sistem Informasi Geografis (GIS) dalam Pemetaan Kerajinan Kain Tenun dan Gerabah untuk Meningkatkan Potensi Kerajinan di Kabupaten Lombok Timur. Infotek: Jurnal Informatika Dan TeknologiInfotek: Jurnal Informatika Dan Teknologi, 1(2), 64-71.

Suhartini, S., Sudianto, A., Gunawan, I., Permana, B. A. C., Ahmadi, H., Fathurrahman, I., Wijaya, L. K., Wasil, M., \& Nurhidayati, N. (2021). Pembinaan kewirausahaan berbasis teknologi untuk mengembangkan jiwa Technopreneurship. ABSYARA: Jurnal Pengabdian Pada Masyarakat, 2(1), 1-7. https://doi.org/10.29408/ab.v2i1.2574

Susandi, D., \& Sukisno, S. (2018). Sistem Informasi Inventaris Berbasis Web di Akademi Kebidanan Bina Husada Serang. JSiI (Jurnal Sistem Informasi), 5(2), 46-50. https://doi.org/10.30656/jsii.v5i2.775

Wirasasmita, R. H., Arianti, B. D. D., Uska, M. Z., Kholisho, Y. N., \& Wardi, Z. (2020). Edukasi Zero Waste Berbasis Teknologi Informasi. ABSYARA: Jurnal Pengabdian Pada Masyarakat, 1(2), 1-8. https://doi.org/10.29408/ab.v1i2.2749

Wulandari, M. S., Noveandini, R., \& Sutarno, S. Digitalisasi Pemetaan UKM Tenun Garut Berbasis Sistem Informasi Geografis sebagai Media Komunikasi dan Pemasaran Produk Lokal. In Seminar Nasional Multi Disiplin Ilmu Unisbank 2015. Stikubank University. 